DOI: 10.12731/wsd-2018-5-62-73

УДК 599.322:678.424-616.911

\title{
СРАВНИТЕЛЬНЫЙ АНАЛИЗ МНОГОЛЕТНЕЙ ЭПИЗООТИЧЕСКОЙ СИТУАЦИИ ПО ОРТОХАНТАВИРУСНОЙ ИНФЕКЦИИ В ПОПУЛЯЦИЯХ АРОDЕМUS AGRARIUS И МICROTUS FORTIS В ПРИРОДНЫХ ОЧАГАХ ЮГА ДАЛЬНЕГО ВОСТОКА РОССИИ
}

\author{
Компанец Г.Г., Иунихина О.В.
}

Цель. Изучить особенности эпизоотического процесса в популяциях мымевидных грызунов - носителей ортохантавирусов Hantaan и Fuzong в природных очагах инфекции Приморского края.

Материалы и методы. Инфицированность ортохантавирусом 14494 Apodeтus agrarius и 2887 Microtus fortis, отловленных в 1981-2016 г2, в разных районах края, оченивали по обнаружению специфического антигена в иммуноферментном анализе или специфических антител в непрямом методе флуоресцирующих антител (НМФА). Для более показательного сравнительного анализа многолетней динамики инфицированности в популяциях грызунов период исследования был разделен на три 12-летних периода (1981-1992 г2, 1993-2004 г2. и 2005-2016 г2.). Статистическая обработка полученных данных производилась с использованием программного обеспечения Statistica 10.0 (Statsoft, США) и статистических калькуляторов предоставленных сервисом http://medstatistic.ru.

Результаты. Полученные результаты многолетней динамики инфицированности ортохантавирусом демонстрируют практически синхронные подъемь/спады инфицированности в популячиях двух видов грызунов, однако, несмотря на доминирование в отловах полевой мыши, за исследованный период отмечена статистически достоверная тенденџия уменьшения активности эпизоотического прочесса в её популяиии. В то же время в популяции M. fortis в биотопах совместного обитания статистически достоверное снижение инфицированности отмечено только в последние 12 лет.

Заключение. Таким образом, в последние годы в луго-полевых биотопах Приморского края отмечено снижение активности эпизоотического процесса в популячиях грызунов - носителей ортохантавируса Hantaan, 
имеющее важное значение для заболеваемости геморрагической лихорадкой с почечным синдромом в регионе.

Ключевые слова: ортохантавирусы; эпизоотический процесс; активность; природные резервуары.

\section{COMPARATIVE ANALYSIS OF MULTI-YEAR EPIZOOTIC SITUATION ON ORTHOHANTAVIRUS INFECTION IN THE POPULATION OF APODEMUS AGRARIUS AND MICROTUS FORTIS IN THE NATURAL FOCI OF THE SOUTH OF FAR EAST OF RUSSIA}

\section{Kompanets G.G., Iunikhina O.V.}

Aim. Characterization of long-term epizootic processes in the populations of murine rodents, the carriers of different orthohantaviruses (Hantaan and Fuzong) in the rural areas of Primorski Krai.

Materials and methods. Total 14494 Apodemus agrarius and $2887 \mathrm{Mi}$ crotus fortis, trapped during 1981-2016 in different foci were examined on the presence of orthohantavirus antigen and/or antibodies with the help of immunoenzyme assay (ELISA) and indirect fluorescent antibodies test (IFAT), subsequently. For clear demonstration the obvious tendencies of long-term infectious processes in the rodent's populations the study period was divided into three 12-years periods (1981-1992, 1993-2004, 2005-2016 2). Statistical analysis was performed using software Statistica 10.0 (Statsoft, СШA) and statistical tools, provided by service of http://medstatistic.ru.

Results. Lon-term dynamics of epizootic processes in the populations of natural hosts of orthohantaviruses Hantaan and Fuzong was demonstrated by similar synchronicity. However, in spite of dominance of A. agrarius in the catching during the study period the rate of infection in the populations of this rodent species is characterized by statistically significant decrease of epizootic activity. While in the population of $M$. fortis in the areas of concomitant habitat the significant decrease of orthohantavirus infection was noted only during last 12 years.

Conclusion. Thus, epizootic activity in the population of rodents - reservoirs of orthohantavirus Hantaan in the step-forest biotopes of Primorsky Krai has been decreased, that was very important and resulted in change of epidemiology of hemorrhagic fever with renal syndrome in the region.

Keywords: orthohantaviruses; epizootic process; activity; natural reservoirs. 
Основным природным резервуаром ортохантавирусов (род Orthohantavirus, семейство Hantaviridae) являются грызуны отряда Rodentia, при этом, считается, что каждый вид ортохантавирусов эволюционно связан с животным - природным носителем одного вида $[1,2]$. Значимость ортохантавирусов определяется их ролью в инфекционной патологии человека, из более чем 90 генотипов, идентифицированных в настоящее время, 22 связаны с заболеваниями людей, включая геморрагическую лихорадку с почечным синдромом (ГЛПС) $[3,4,5,6]$.

В разных биотопах территории Приморского края циркулирует несколько патогенных для человека ортохантавирусов, в частности, вирус Hantaan циркулирует в популяциях полевой мыши Apodemus agrarius (геновариант Far East -луго-полевые биотопы) и восточноазиатской мыши A.peninsulae (геновариант Amur - лесные биотопы) [7]. На этих же территориях обитают и носители непатогенных для человека ортохантавирусов Fuzong и Hokkaido (в популяциях Microtus fortis и Myodes rufocanus, соответственно) [8]. При эпизоотической оценке популяций грызунов - носителей ортохантавирусов на территории Приморского края особое внимание уделяется полевой мыши, поскольку результаты многолетних наблюдений за очагами ортохантавирусной инфекции в крае свидетельствуют о том, что наиболее тяжело протекают случаи, связанные именно с заражением в ее ареале $[9,10,11,12]$. Сравнительный анализ эпизоотической и популяционной активности этих двух экологически близких видов грызунов может позволить раскрыть некоторые особенности механизмов их адаптации к условиям обитания и выявить влияние совместной циркуляции на эпидемические проявления ГЛПС.

Цель раскрыть многолетние особенности эпизоотического процесса ортохантавирусов Hantaan и Fusong в популяциях A. agrarius и M. fortis, в природных очагах Приморского края.

\section{Материалы и методы}

Ретроспективно проанализированы материалы, полученные во время экспедиционных и стационарных исследований (1986-2016 гг.) на энзоотичных территориях Приморского края. Отлов проводили ежегодно, в четыре сезона: весной (апрель-май), летом (июль), осенью (сентябрь-октябрь) и, по возможности, зимой (декабрь-февраль). Отловы мелких млекопитающих проводились ловушками Геро на учетных линиях, которые располагались на местности таким образом, чтобы охватывались основные ландшафтные площади. За период наблюдений отловлено 14494 A. agrarius и $2887 \mathrm{M}$. fortis. Определение видов грызунов проводилось на основе анализа окраски 
шкурки, краниальных и экстерьерных признаков [13]. При отлове грызунов руководствовались пунктом 2.11. «Требования к порядку отлова, транспортирования и содержания диких позвоночных животных и членистоногих при проведении экспериментальных работ» санитарных правил СП 1.3.3118-13. Инфицированность мышевидных грызунов устанавливали по наличию антигена ортохантавируса в органах и специфических антител в крови зверьков.

Антиген ортохантавируса выявляли в 10-20\% суспензии органов грызунов с помощью иммуноферментного анализа (ИФА) с использованием коммерческой тест-системы «Хантагност» производства ФГБНУ «Федеральный научный центр исследований и разработки иммунологических препаратов имени М.П. Чумакова», РАН. Специфические антитела в сыворотках крови грызунов определяли с помощью непрямого метода флюоресцирующих антител (НМФА) и коммерческой тест-системы «Диагностикум геморрагической лихорадки с почечным синдромом» этого же производителя.

Статистическая обработка полученных данных производилась с использованием программного обеспечения Statistica 10.0 (Statsoft, CША) и статистических калькуляторов предоставленных сервисом http:// medstatistic.ru [14].

\section{Результаты и обсуждение}

Результаты сравнения многолетних показателей инфицированности ортохантавирусом, представленные на рисунке 1, демонстрируют наличие практически синхронных подъемов/спадов инфицированности в популяциях двух видов грызунов.

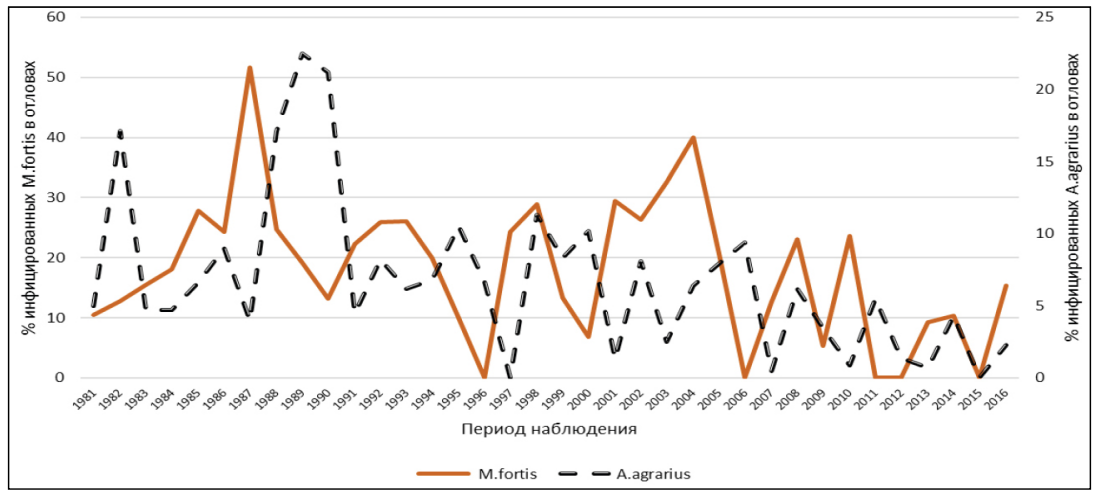

Рис. 1. Многолетняя динамика инфицированности ортохантавирусом популяций M.fortis и A.agrarius 
Для дальневосточной полевки характерны регулярные подъемы численности/инфицированности каждые 3-4 года, для полевой мыши такая цикличность также присутствует, однако носит менее регулярный, нестабильный характер. При этом, для обоих видов грызунов наиболее высокие показатели инфицированности отмечены в 90-е годы прошлого века: от $17,1 \pm 1,58 \%$ до $22,5 \pm 1,74 \%$ для полевой мыши, и 51,6 $\pm 3,66 \%$ для дальневосточной полевки. Тогда как в следующие годы отмечается явная тенденция уменьшения численности грызунов этих видов, и соответственно их инфицированности. За последний 15 лет показатель инфицированности в популяции полевой мыши не превышал 10,0\%, а относительно высокие показатели инфицированности дальневосточной полевки в этот период (от 15,4\% до 40\%) получены при анализе менее значительной выборки обследованных грызунов.

С целью сравнительного анализа многолетней динамики инфицированности в популяциях грызунов двух видов период исследования был разделен на три 12-летних периода (1981-1992 гг., 1993-2004 гг. и 20052016 гг.). Средние показатели инфицированности грызунов (в совокупности с показателями отловов) в данные периоды представлены в таблице 1 .

Таблица 1.

Показатели инфицированности ортохантавирусом популяций $A$. agrarius и $M$. fortis за 1981-2016 гг.

\begin{tabular}{|c|c|c|c|c|}
\hline & \multicolumn{4}{|c|}{ Период наблюдения } \\
\hline Популяции грызунов & $\begin{array}{c}1 \\
1981-1992 \text { гг }\end{array}$ & \begin{tabular}{|c|}
2 \\
$1993-2004$ гг
\end{tabular} & \begin{tabular}{|c|}
3 \\
$2005-2016$ гг
\end{tabular} & $\begin{array}{c}\text { Итого } \\
1981-2016 \text { гг }\end{array}$ \\
\hline $\begin{array}{l}\text { A. agrarius, } \\
\text { инфицированность } \\
\text { (среднее значение, } \\
\text { М } \pm \text { m, \%) /общее коли- } \\
\text { чество исследованных } \\
\text { особей }(\mathrm{n}=)\end{array}$ & $\begin{array}{c}8,91 \pm 0,3 \\
/ \mathrm{n}=18719\end{array}$ & $\begin{array}{c}7,22 \pm 0,54 \\
/ \mathrm{n}=2300\end{array}$ & $\begin{array}{c}4,09 \pm 0,34 \\
/ \mathrm{n}=3475\end{array}$ & $\begin{array}{l}7,29 \pm 0,22 \\
/ \mathrm{n}=14494\end{array}$ \\
\hline $\begin{array}{l}\text { M. fortis, } \\
\text { инфицированность } \\
\text { (среднее значение, } \\
\text { М } \pm \mathrm{m}, \% \text { ) /общее коли- } \\
\text { чество исследованных } \\
\text { особей }(\mathrm{n}=)\end{array}$ & $\begin{array}{c}21,95 \pm 0,91 \\
/ \mathrm{n}=2073\end{array}$ & $\begin{array}{c}24,16 \pm 2,7 \\
/ \mathrm{n}=389\end{array}$ & $\begin{array}{c}13,885 \pm 1,68 \\
/ \mathrm{n}=425\end{array}$ & $\begin{array}{c}21,06 \pm 0,76 \\
/ \mathrm{n}=2887\end{array}$ \\
\hline
\end{tabular}

Очевидно, что в 1-й период было исследовано наибольшее количество грызунов, при этом уловистость полевой мыши во все периоды значительно превышала показатели дальневосточной полевки. Однако показатели 
инфицированности M.fortis всегда были статистически достоверно выше показателей A.agrairus: $\mathrm{p} \leq 0,005$ при сравнении показателей в каждый из трех периодов наблюдения и суммарных показателей. Что касается инфицированности, то для полевой мыши подтверждена постепенная тенденция снижения её показателей, так как получена статистически достоверная разность между показателями во все периоды наблюдения: $\mathrm{p} \leq 0,05$ (1 vs 2), $\mathrm{p} \leq 0,005$ ( 1 vs 3 ) и $\mathrm{p} \leq 0,005$ ( 2 vs 3 ). В то же время в популяции дальневосточной полевки статистически достоверное снижение инфицированности отмечено только в третий период, в сравнении с двумя предыдущими: $\mathrm{p}=0,438031$ ( 1 vs 2$), \mathrm{p} \leq 0,005$ ( 1 vs 3 ) и $\mathrm{p} \leq 0,005$ (2 vs 3 ).

Полученные результаты, характеризующие сходство эпизоотических процессов в популяциях грызунов этих видов, очевидно, связаны с одинаковыми условиями обитания. Как правило, благоприятными для обитания полевой мыши условиями являются хорошо увлажненные места в зоне лесостепи, смешанных и широколиственных лесов, кустарниковые и открытые биотопы. Полевая мышь может распространяться на другие территории по речным долинам и мелиорированным агроценозам, в том числе, по антропогенным ландшафтам $[13,15]$. В то же время известно, что M. fortis селится по поймам и заболоченным участкам степной и лесной зон, горным падям, берегам речек и озер [16], хотя нередко встречается на сельскохозяйственных землях, значительно удаленных от воды, и, как полевая мышь, может наносить серьезный вред сельскохозяйственным угодьям.

На территории Приморского края ареалы грызуны этих двух видов практически совпадают $[15,16,17]$ и охватывают лесостепные западные и центральные районы, расположенные на Приханкайской низменности, а также в долинах крупных рек Уссури и Раздольная. В то же время, с учетом уловистости, по всей видимости, Microtus fortis не является доминирующим видом, ее участие в населении грызунов значительно ниже, чем полевой мыши, которая является наиболее многочисленным видом, часто доминирует в населении мелких млекопитающих на юге дальневосточного региона [18].

Полученные результаты о снижении активности эпизоотического процесса в популяциях полевой мыши хорошо согласуются с данными, полученными нами ранее [19]. Установлено, что в последние годы в этиологии ГЛПС, регистрируемой ежегодно на территории Приморского края, ведущую роль играет вариант Amur вируса Hantaan, циркулирующий в популяциях восточно-азиатской мыши A.peninsulae, обитающей, преимущественно, в лесных биотопах. Это непосредственно отражается в эпи- 
демиологических особенностях ортохантавирусной инфекции, особенно, в сезонной динамике заболеваемости и социально-профессиональной структуре заболевших [20].

Таким образом, можно предположить, что, несмотря на высокие показатели инфицированности ортохантавирусом, по всей видимости, роль популяции M. fortis, в эпидемиологии геморрагической лихорадки с почечным синдромом в регионе незначительна. Во-первых, грызуны этого вида являются носителем ортохантавируса Fusong, патогенность которого для людей до настоящего времени не подтверждена, и во-вторых, из-за того, что в ареалах совместного обитания доминирует полевая мышь - носитель патогенного для человека вируса Hantaan, а дальневосточная полевка является второстепенным содоминантом.

Сложившаяся на территории Приморского края ситуация, характеризующаяся снижением в последние годы эпизоотической активности в популяциях грызунов - носителей двух разных ортохантавирусов, по всей видимости, обусловлена уменьшением кормовой базы. Это непосредственно связано с хозяйственной деятельностью человека, а именно, с изменением структуры сельскохозяйственной деятельности в крае (уменьшение посевов злаков с увеличением площадей, занятых под овощные культуры), а также с фрагментацией мест обитания диких грызунов.

\section{Выводы}

1. Многолетняя динамика численности/ инфицированности в популяциях Apodemus agrarius и Microtus fortis в очагах луго-полевого типа носит выраженный синхронный характер.

2. Однако, в популяциях полевой мыши - носителя вируса Hantaan в последние годы отмечается отчетливая тенденция снижения эпизоотической активности, с длительной депрессией с нерегулярными подъемами, невысокими и статистически незначимыми показателями инфицированности на фоне низкой уловистости.

Информация о конфликте интересов. Авторы статьи заявляют об отсутствии конфликта интересов.

Информация о спонсорстве. Данное исследование поддержано грантом ДВО РАН № 17-I-1-041 э «Организация и проведение экспедиций по изучению современного состояния природных очагов социально-значимых хантавирусных и клещевых инфекций в лесных экосистемах юга Дальнего Востока (Приморского края)». 


\section{Список литературы}

1. Global Diversity and Distribution of Hantaviruses and Their Hosts / Milholland M.T., Castro-Arellano I., Suza G., Garcia-Pen G.E., Lee T.E., Rohde R.E., Aguirre A.A., Mills J.N. // EcoHealth. 2018. Vol.15. № 1, pp. 163-208.

2. Plyusnin A., Morzunov S. Virus evolution and genetic diversity of hantaviruses rodent hosts // Curr. Top. Microbiol. Immunol. 2001. Vol. 256, pp. 47-7.

3. Bi Z., Formenty P.B.H., Roth C.E. Hantavirus infection: a review and global update // Journal of Infection in Developing Countries. 2008. Vol. 2. № 1, pp. 3-23.

4. Kruger D.H., Schonrich G., Klempa B. Human pathogenic hantaviruses and prevention of infection // Human Vaccines. 2011. Vol. 7, pp. 685-693.

5. Taxonomy of the family Arenaviridae and the order Bunyavirales: update 2018 / Maes P., Alkhovsky S.V., Bào Y., Beer M. et al. // Arch. Virol. 2018. Vol.163. № 8, pp. 2295-2310.

6. Uncovering the mysteries of hantavirus infections / Vaheri A., Strandin T., Hepojoki J., Sironen T., Henttonen H., Makela S., Mustonen J. // Nature Reviews Microbiology. 2013. Vol. 11, pp. 539-550.

7. Isolation and characterization of hantaviruses in Far East Russia an etiology of hemorrhagic fever with renal syndrome in the region / Kariwa H., Yoshikawa K., Tanikawa Y., Seto T., Sanada T., Saasa N., Yoshii K., Takashima I., Ivanov L.I., Slonova R.A., Zakharycheva T.A., Nakamura I., Yoshimatsu K., Arikawa J. // American Journal of Tropical Medicine and Hygiene. 2002. Vol. 86. N 3, pp. 545-543.

8. Хантавирусы, циркулирующие в полевках Microtus fortis и Microtus maximowiczii / Яшина Л.Н., Иванов Л.И., Слонова Р.А., Компанец Г.Г., Гуторов В.В., Кушнарева Т.В., Здановская Н.И. // Тихоокеанский медицинский журнал. 2008. № 2 (32). С. 47-49.

9. Хантавирусная инфекция в Приморском крае - эпидемиологическая ситуация в очагах циркуляции разных серотипов вируса / Слонова Р.А., Кушнарева Т.В., Компанец Г.Г., Максема И.Г., Симонова Т.Л., Симонов С.Б. // Журнал микробиологии, эпидемиологии и иммунобиологии. 2006. № 3. С. 74-77.

10. Сопряженность эпидемического процесса хантавирусной инфекции с активностью эпизоотического процесса в популяциях мышей рода Apodemus / Слонова Р.А., Кушнарева Т.В., Максема И.Г., Компанец Г.Г., Иунихина О.В. // Эпидемиология и инфекционные болезни. 2012. № 3. С. 18-22.

11. Особенности эпизоотического процесса в популяциях эпидемически значимых мышей рода Apodemus - природных хозяев возбудителей ГЛПС / Кушнарева Т.В., Слонова Р.А., Максема И.Г., Компанец Г.Г., Иунихина О.В., Кушнарев Е.Л. // Дальневосточный журнал инфекционной патологии. 2012. № 20 (20). С. 57-64. 
12. Кушнарева Т.В. Эпизоотологические параметры циркуляции гетерогенной популяции хантавирусов на юге Дальнего Востока России // Международный журнал экспериментального образования. 2015. № 5-1. С. 9-11.

13. Громов И.М., Ербаева М.А. Млекопитающие фауны России и сопредельных территорий. Зайцеобразные и грызуны. Спб.: ЗИН РАН, 1995. 522 с.

14. Медицинская статистика. URL: http://medstatistic.ru/calculators.html (дата обращения 23.10.2018).

15. Роль мышевидных грызунов в циркуляции хантавирусов в природных экосистемах Приморья / Симонов С.Б., Симонова Т.Л., Симонов П.С., Борисова Д.С. Дальнаука: 2014. 180 с.

16. Лапин А.С. Мелкие млекопитающие южной части Хабаровского края и Еврейской автономной области (фауна, экология, эпизоотологическое значение): Автореф дисс.....канд.биол.наук. Хабаровск, 2013, 25 с.

17. Хантавирусная инфекция в Приморском крае. Медико-географический атлас / Слонова Р.А., Симонов С.Б., Компанец Г.Г., Симонова Т.Л., Кушнарева Т.В., Алленов А.В., Мурначев Г.П., Яшина Л.Н., Симонов П.С., Хоменко Т.В., Борзов В.П. // Владивосток. 2007. С. 48.

18. Костенко В.А. Грызуны (Rodentia) Дальнего Востока России: Автореф дисс.....доктора биол.наук. Владивосток, 1997, 46 с.

19. Основные тенденции развития эпидемического процесса геморрагической лихорадки с почечным синдромом на юге Дальнего Востока России / Компанец Г.Г., Иунихина О.В., Кузнецова Н.А., Потт А.Б., Гуськова Е.В. // Журнал научных статей Здоровье и образование в ХХІ веке. 2017. Т. 19. № 11. С. 140-145.

20. Кузнецова Н.А., Компанец Г.Г. Социально-профессиональная структура заболеваемости ГЛПС в разные периоды хозяйственно-экономической деятельности в Приморском крае // Здоровье. Медицинская экология. Наука. 2017. № 5 (72). C. 10-15.

\section{References}

1. Milholland M. T., Castro-Arellano I., Suza G., Garcia-Pen G.E., Lee T.E., Rohde R.E., Aguirre A.A., Mills J.N. Global Diversity and Distribution of Hantaviruses and Their Hosts. EcoHealth, 2018, Vol.15, № 1, pp. 163-208.

2. Plyusnin A., Morzunov S. Virus evolution and genetic diversity of hantaviruses rodent hosts. Curr. Top. Microbiol. Immunol, 2001, Vol. 256, pp. 47-7.

3. Bi Z., Formenty P.B.H., Roth C.E. Hantavirus infection: a review and global update. Journal of Infection in Developing Countries, 2008, Vol. 2, № 1, pp. 3-23.

4. Kruger D.H., Schonrich G., Klempa B. Human pathogenic hantaviruses and prevention of infection. Human Vaccines, 2011, Vol. 7, pp. 685-693. 
5. Taxonomy of the family Arenaviridae and the order Bunyavirales: update 2018 / Maes P., Alkhovsky S.V., Bào Y., Beer M. et al. Arch. Virol., 2018, Vol.163, № 8, pp. 2295-2310.

6. Vaheri A., Strandin T., Hepojoki J., Sironen T., Henttonen H., Makela S., Mustonen J. Uncovering the mysteries of hantavirus infections. Nature Reviews Microbiology, 2013, Vol. 11, pp. 539-550.

7. Kariwa H., Yoshikawa K., Tanikawa Y., Seto T., Sanada T., Saasa N., Yoshii K., Takashima I., Ivanov L.I., Slonova R.A., Zakharycheva T.A., Nakamura I., Yoshimatsu K., Arikawa J. Isolation and characterization of hantaviruses in Far East Russia an etiology of hemorrhagic fever with renal syndrome in the region. American Journal of Tropical Medicine and Hygiene. 2002. Vol. 86. N 3, pp. 545-543.

8. Yashina L.N., Ivanov L.I., Slonova R.A., Kompanets G.G., Gutorov V.V., Kushnareva T.V., Zdanovskaya N.I. Hantavirusy, cirkuliruyushchie v polevkah Microtus fortis i Microtus maximowiczii [Hantaviruses circulating in the voles Microtus fortis and Microtus maximowiczii]. Tihookeanskij medicinskij zhurnal [Pacific Medical Journal], 2008, № 2 (32), pp. 47-49.

9. Slonova R.A., Kushnareva T.V., Kompanets G.G., Maksema I.G., Simonova T.L., Simonov S.B. Hantavirusnaya infekciya v Primorskom krae - ehpidemiologicheskaya situaciya $v$ ochagah cirkulyacii raznyh serotipov virusa [Hantavirus infection in Primorskiy Krai - epidemiological situation in the foci of circulation of different virus serotypes]. Zhurnal mikrobiologii, ehpidemiologii i immunobiologii [Journal of Microbiology, Epidemiology and Immunobiology], 2006, № 3, pp. 74-77.

10. Slonova R.A., Kushnareva T.V., Maksema I.G., Kompanets G.G., Iunikhina O.V. Sopryazhennost' ehpidemicheskogo processa hantavirusnoj infekcii s aktivnost'yu ehpizooticheskogo processa v populyaciyah myshej roda Apodemus [Contingency of the Epidemic Process of Hantavirus Infection with Activity of Epizootic Process in Populations of Mice of the Genus Apodemus]. Epidemiologiya i infekcionnye bolezni [Epidemiology and Infectious Diseases], 2012, № 3, pp. 18-22.

11. Kushnareva T.V., Slonova R.A., Maksema I.G., Kompanets G.G., Iunikhina O.V., Kushnarev E.L. Osobennosti ehpizooticheskogo processa v populyaciyah ehpidemicheski znachimyh myshej roda Apodemus - prirodnyh hozyaev vozbuditelej GLPS [Features of Epizootic Process in Populations of Epidemically Significant Apodemus Mice - Natural Hosts of Ethiological Agents of Hemorrhagic fever with Renal Syndrome]. Dal'nevostochnyj zhurnal infekcionnoj patologii [Far-Eastern Journal of Infectious Pathology], 2012, № 20 (20), pp. 57-64.

12. Kushnareva T.V. Epizootologicheskie parametry cirkulyacii geterogennoj populyacii hantavirusov na yuge Dal'nego Vostoka Rossii [Epizootological parameters of heterogenic hantavirus population circulation in the south of Far East 
Russia]. Mezhdunarodnyj zhurnal ehksperimental'nogo obrazovaniya [International Journal of Experimental Education], 2015, № 5-1, pp. 9-11.

13. Gromov I.M., Erbaeva M.A. Mlekopitayushchie fauny Rossii i sopredel'nyh territorij. Zajceobraznye i gryzuny [Mammals in Fauna of Russia and Cross-Border Regions]. Saint-Petersburg: ZIRA RAS, 1995, pp. 522.

14. Medicinskaya statistika [Medical Statistics]. http://medstatistic.ru/calculators. html (date of access 23.10.2018).

15. Simonov S.B., Simonova T.L., Simonov P.S., Borisova D.S. Rol' myshevidnyh gryzunov v cirkulyacii hantavirusov v prirod-nyh ehkosistemah Primor'ya [The role of Muridae rodents of the hantavirus circulation in the natural ecosystems of Primorye]. Dal'nauka [Dalnauka]: 2014. 180 p.

16. Lapin A.S. Melkie mlekopitayushchie yuzhnoj chasti Habarovskogo kraya i Evrejskoj avtonomnoj oblasti (fauna, ehkologiya, ehpizootologicheskoe znachenie) [Small Mammals in Southern Part of Khabarovskiy Krai and Jewish Autonomy Region (fauna, ecology, epizootological importance]: Avtoref diss..... kand.biol.nauk [Author's abstract of Candidate of Biological Sciences Degree]. Khabarovsk, 2013, 25 p.

17. Slonova R.A., Simonov S.B., Kompanets G.G., Simonova T.L., Kushnareva T.V., Allenov A.V., Murnachev G.P., Yashina L.N., Simonov P.S., Homenko T.V., Borzov V.P. Hantavirusnaya infekciya v Primorskom krae. Mediko-geograficheskij atlas [Hantavirus Infection in Primorskiy Krai. Medical-Geographical Atlas]. Vladivostok. 2007. P. 48.

18. Kostenko V.A. Gryzuny (Rodentia) Dal'nego Vostoka Rossii [Rodents (Rodentia) of Far East of Russia]: Avtoref diss.....doct.biol.nauk [Author's abstract of Doctor of Biological Sciences Degree]. Vladivostok, 1997, 46 p.

19. Kompanets G.G., Iunikhina O.V., Kuznetsova N.A., Pott A.B., Gus'kova E.V. Osnovnye tendencii razvitiya ehpidemicheskogo processa gemorra-gicheskoj lihoradki s pochechnym sindromom na yuge Dal'nego vostoka Rossii [The Main Trends in the Development of the Epidemic Process of Hemorrhagic Fever with Renal Syndrome in the South of the Far East of Russia]. Zhurnal nauchnyh statej Zdorov'e i obrazovanie v XXI veke [Health and Education in the XXI Century]. 2017. Vol. 19. № 11, pp. 140-145.

20. Kuznetsova N.A., Kompanets G.G. Social'no-professional'naya struktura zabolevaemosti GLPS v raznye periody hozyajstvenno-ehkonomicheskoj deyatel'nosti v Pri-morskom krae [Social and professional structure of HFRS morbidity during the different periods of economics in the Primorsky region]. Zdorov'e. Medicinskaya ehkologiya. Nauka [Health. Medical Ecology. Science]. 2017, № 5 (72), pp. 10-15. 


\section{ДАННЫЕ ОБ АВТОРАХ}

Компанец Галина Геннадиевна, кандидат медицинских наук, ведущий научный сотрудник лаборатории экспериментальной вирусологии Научно-исследовательский институт эпидемиологии и микробиологии имени Г.П. Сомова

ул. Сельская, 1, г. Владивосток, 690087, Российская Федеращия galkom1965@gmail.com

Иунихина Ольга Викторовна, кандидат медицинских наук, научный сотрудник лаборатории экспериментальной вирусологии Научно-исследовательский институт эпидемиологии и микробиологии имени Г.П. Сомова

ул. Сельская, 1, г. Владивосток, 690087, Российская Федерачия olga_iun@inbox.ru

\section{DATA ABOUT THE AUTHORS}

Kompanets Galina Gennadievna, Candidate of Medical Sciences, Leading Researcher, Laboratory of Experimental Virology Research Somov Institute of Epidemiology and Microbiology 1, Selskaya Str., Vladivostok, 690087, Russian Federation galkom1965@gmail.com

Iunikhina Olga Viktorovna, Candidate of Medical Sciences, Researcher of the Laboratory of Experimental Virology Research Somov Institute of Epidemiology and Microbiology 1, Selskaya Str., Vladivostok, 690087, Russian Federation olga_iun@inbox.ru 